\title{
¿SE BRINDA UN TRATAMIENTO ADECUADO A LOS RESIDUOS URBANOS EN LOS BOTADEROS MUNICIPALES?
}

\author{
¿IS AN ADEQUATE TREATMENT PROVIDED FOR URBAN WASTE \\ IN MUNICIPAL BOTTLES?
}

\section{Sr. Editor:}

Los residuos urbanos que son generados diariamente, aproximadamente 17000Tn/día, heterogéneos en su composición, variables en su complejidad en función al tiempo y se incrementan con el aumento de la población. La búsqueda de la estabilización de los residuos urbanos conduce a la generación de varias alternativas, entre estas están los botaderos o vertederos Municipales, rellenos sanitarios, plantas de biogás entre otras (Laine, A., et al, 2016 y Runfola, J., \& Gallardo, A., 2009).

Los botaderos Municipales locales presentan alta densidad de materia orgánica, en proceso de descomposición microbiana (generando lixiviados que pueden afectar la composición de la napa freática) facilitando la atracción de vectores mecánicos de microorganismos patógenos, pero también se observa residuos de latex, embase plásticos de variada densidad, restos de plásticos, poliestireno expandido, desechos del sector salud, cerdos parcialmente quemados, montículos de cascara de huevos y la presencia de roedores, y recicladores que no cuentan con medidas de bioseguridad (Campos-Rodríguez, R., \& SotoCórdoba, S. M. 2014, Carril, V., \& Vásquez, A., 2015 y Vásquez Vásquez, F., 2010).

En los botaderos Municipales en Perú se practica la quema a cielo abierto (esta es una práctica inadecuada, debería ser por incineración en hornos, con filtros) de los residuos urbanos que no seleccionados y luego sofocado con suelo (debe ser arcilloso) del lugar, armando estratos de 6 capas en promedio, que después el piso superior será camino y las zonas intermedias altas están humeantes y otras son nido de roedores. Los inconvenientes son: pocos recicladores respecto de la densidad de residuos urbanos, lo que facilita la atracción de gallinazos, gaviotas, roedores (que pueden ser portadores de endoparasitos y/o ectoparasitos) la movilización de microorganismos patógenos por la emisión de sustancias volátiles derivadas de la pudrición de los residuos orgánicos vegetales o animales que actúan como atractantes (Jaramillo, J., 2002).

La quema de los residuos genera tres tipos de contaminantes: La contaminación por partículas menores a 10um, que tienen gran dificultad para salir del aparato respiratorio, la composición química y/o biológica de la partícula, los compuestos químicos gaseosos con efecto cancerígeno (por ejemplo dioxinas derivados de la quema de trozos de llantas plásticos, pvc) y la liberación del dióxido de carbono, un gas de efecto invernadero, esto genera un problema de medio ambiente (Bonfanti, F. A., 2004 y Moya, M. T. F., et al, 2011).

Los cerdos presentes en botadero son derivados del descarte, ya sea por haber muerto por una infección bacteriana o por estar parasitados, son parcialmente quemados superficialmente, siendo alimento para gallinazos, roedores y gaviotas. Estos podrían movilizar estos parásitos y bacterias (Staphylococcus aureus, Pseudomonas aeruginosa, Streptococcus faecalis y Escherichia coli) a otras coordenadas a través de sus heces (Burchard, L. 1978).

En las condiciones de funcionamiento actual los botaderos Municipales (unos tienen perímetro incompleto-solo la entrada- o no tienen definidos su límites y restricciones de acceso) son un problema de salud pública: Falta implementar políticas de educación en bioseguridad, que sea practicable por los recicladores y por todo personal que lleve residuos (prohibiendo el ingreso de niños como recicladores y consumo de alimentos), controles de desinfección ingreso y salida de vehículos, salas de descontaminación del personal, cambio frecuente de los filtros de las mascaras de gases y partículas, selección de residuos desde la fuente de colecta, implementar sistemas de compostaje industrial de los residuos urbanos con la finalidad de evitar la quema de residuos Incrementar la educación de reciclaje adecuado y sistemas de compostaje (u otros procesos o bioprocesos) tanto en colegios, universidades y comunidades (Martínez Cuesta, M. P., 2017 y Unchupaico, E., 2017).

Huberto Noriega Córdova, Facultad de Ciencias, Universidad Nacional José Faustino

Sánchez Carrión, Perú

e-mail: hnoriega@unjfsc.edu.pe

Juana Córdova Matos, Facultad de Educación, Universidad Nacional José Faustino

Sánchez Carrión, Perú

\section{REFERENCIAS BIBLIOGRÁFICAS}

Bonfanti, F. A. (2004). La incorrecta gestión de los residuos sólidos urbanos y su incidencia en la calidad de vida de la población de Resistencia. Universidad Nacional del Nordeste. Comunicaciones Científicas y Tecnológicas. Argentina. 
Burchard, L. (1978). Estudio del jote (Coragyps atratus foetens, licchtenstein) en valdivia: etologia carroñera y rol en diseminación de agentes patógenos. Archivos de Medicina Veterinaria, 10(2), 111-127.

Campos-Rodríguez, R., \& Soto-Córdoba, S. M. (2014). Análisis de la situación del estado de la Gestión Integral de Residuos (GIR) en el cantón de Guácimo, Costa Rica. Revista Tecnología en Marcha, 27(1), 114-124.

Carril, V., \& Vásquez, A. (2015). Evaluación de los procesos de gestión ambiental de residuos sólidos hospitalarios en el Departamento de Tumbes. Manglar, 10(2), 67-76.

Jaramillo, J. (2002). Guía para el diseño, construcción y operación de rellenos sanitarios manuales. Colombia: Centro Panamericano de Ingeniería Sanitaria y Ciencias delAmbiente (ops/cepis).

Laine, A., Sulkinoja, M., \& Hytti, J. (2016). Programa de preparación de NAMA residuos solidós en Peru.
Martínez Cuesta, M. P. (2017). Diseño de un plan integral de gestión de residuos sólidos para una institución de educación media en Bogotá (Bachelor's thesis, Universidad Militar Nueva Granada).

Moya, M. T. F., Alonso, M. L., Lobo, J. G., \& Plaza, M. J. D. (2011). Dioxinas y medio ambiente. Revista de Salud Ambiental, 11(1-2), 52-63.

Runfola, J., \& Gallardo, A. (2009). Análisis comparativo de los diferentes métodos de caracterización de residuos urbanos para su recolección selectiva en comunidades urbanas. In II Simposio Iberoamericano de Ingeniería de Residuos. Barranquilla, Colombia (Vol. 24).

Vásquez Vásquez, F. (2010). Evaluación del índice de calidad del agua en el área de influencia del botadero municipal de Tarapoto sector Yacucatina San Martin-Perú.

Unchupaico, E. (2017). Actitud y comportamiento hacia la clasificación y reciclaje de residuos sólidos en estudiantes de ingeniería de una universidad agrícola. 